\title{
Uncovering health literacy: Developing a remotely administered questionnaire for determining health literacy levels in health disparate populations
}

\author{
Thomas C. Shaw \\ Department of Political Science and Criminal Justice, University of South Alabama, Mobile, United States \\ Correspondence: Thomas C. Shaw. Address: Department of Political Science and Criminal Justice, University of South \\ Alabama, Mobile, AL 36688, United States. E-mail: tshaw@southalabama.edu \\ Received: March 25, 2014 \\ DOI : $10.5430 /$ jha.v3n4p149 \\ Accepted: June 8, 2014 \\ URL: http://dx.doi.org/10.5430/jha.v3n4p149
}

\begin{abstract}
Introduction: Low health literacy contributes to health disparities. We sought to develop and evaluate a remotely administered tool to measure health literacy in health disparate populations. The basic research design involved asking the remotely administered questions in conjunction with an existing and valid measure of health literacy, the S-TOFHLA, to a non-representative convenience sample of individuals drawn from lower income communities. The measures of the remotely administered questions were then correlated with the results of the S-TOFHLA to determine if there was a connection between the two measures. We found a statistically significant correlation between a single question in the remotely administered survey and the validated S-TOFHLA measure. This research supports previous work that points to the importance of just a single remotely administered question in terms of correspondence with the S-TOFHLA.
\end{abstract}

Objective: Develop a questionnaire that can be remotely administered to check for Health Literacy.

Methods: Correlation analysis is conducted between various questions and S-TOFHLA scores to determine criterion validity.

Results: A single question, "How confident are you in filling out medical forms by yourself?” outperforms other measures in correlating with the S-TOFHLA scores.

Conclusions: Further assessment of the confidence question both in isolation and in conjunction with other literacy identifiers should be conducted. Also, this question should be tested against other measures of health literacy beyond the S-TOFHLA.

\section{Key words}

Health disparities, Healthcare, Literacy, Health literacy, S-TOFHLA, Communication

\section{I ntroduction}

Health literacy is an important topic that impacts society and cuts across socio-economic strata. This research attempts to construct a remotely administered questionnaire for measuring health literacy. The measures proposed herein are compared with an existing measure of health literacy, the S-TOFHLA. This paper briefly examines the importance of 
health literacy, outlines the structure of how the study was conducted, and examines the correlation between the measures developed with the S-TOFHLA.

\subsection{The importance of health literacy and the need for a remotely administered questionnaire}

Health literacy is a key aspect related to patient health and is an ongoing problem in the United States affecting upwards of 90 million people or 50 percent of the adult population ${ }^{[1-5]}$. While the issue of health literacy cuts across all sectors of society ${ }^{[6]}$, it is also a disparities issue because it tends to have stronger impacts on disadvantaged groups ${ }^{[2,7]}$. Patients must be able to understand their clinical providers as well as read and comprehend health related instructions in order to receive maximum benefit from health care services. Poor health literacy impacts compliance when patients do not know when to take medications or schedule follow-up appointments. It can negatively impact informed consent procedures, and it adversely affects access to services when patients do not understand the rights and responsibilities associated with Medicaid and other forms of insurance ${ }^{[8-10]}$. A lack of health literacy has been shown to be related to a number of detrimental health conditions including: poorer health ${ }^{[11-14]}$; poorer control of asthma, diabetes, and hypertension ${ }^{[15,16]}$; higher health care use ${ }^{[17]}$; increased hospitalizations ${ }^{[18,19]}$; increased violence ${ }^{[20]}$; premature death ${ }^{[21]}$; and, higher health costs ${ }^{[22-24]}$.

While the National Adult Literacy Survey ${ }^{[3]}$ demonstrates that low health literacy is a problem that transcends the poor and disadvantaged, it remains difficult to economically assess the health literacy of broader populations. Such assessments require the administration of in-person surveys ${ }^{[25]}$, which are more expensive and time-consuming than other survey methodologies such as telephone, web-based, and mail surveys ${ }^{[26]}$. Thus, research tends to focus on low-income health clinics where health literacy is more variable and little attention is given to assessing health literacy in broader populations.

This research attempts to fill this gap by developing a health literacy measurement instrument that could be remotely administered using telephone, web-based, and/or mail survey methods. A key aspect of this research and the development of such an instrument is establishing its validity ${ }^{[27]}$. Using the method of criterion validity this research compares through correlation analysis the questions developed herein with an existing measure of health literacy, the S-TOFHLA ${ }^{[28]}$. Such a method is justified given that the basis for establishing the validity of the Rapid Estimate of Adult Literacy in Medicine (REALM) is its correlation with the TOFHLA .84 and the S-TOFHLA $.80^{[29]}$.

The long-term benefit of establishing a remotely administered instrument is significant. The specific hypothesis of whether poor health literacy is a widespread or localized phenomenon could be more fully tested. The impact of answering this question should not be underestimated. If poor health literacy is in fact as widespread as believed, statistics to this effect could play a major role in influencing and changing clinical provider behavior toward patients. Also, it would provide additional impetus for programs addressing health literacy. Further, such an instrument could be used to establish baselines and collect follow-up information in a cost-effective way across any number of populations/geographic areas (e.g., communities, cities, regions, states, the nation as a whole). For example, a community may want to establish its baseline level of health literacy prior to enacting efforts to improve health literacy and/or improve patient/provider interactions. Follow-up surveys could then be conducted to determine if health literacy levels had improved or remained the same over time.

\subsection{Study overview}

The specific objectives of the study included:

- Develop a set of questions related to a person's health care experience, comprehension, and literacy that can be remotely administered (by mail or telephone).

- Interview patients in low-income communities (to achieve variability in terms of health literacy). 
- Analyze the questions developed above to determine which questions correlate well with the health literacy scores from the S-TOFHLA thereby establishing the validity of the remotely administrable questions.

\section{Methods}

The survey was conducted in-person with a non-representative convenience sample in low-income areas of Mobile, Alabama. IRB approval for the project (10-097) was obtained on May 12, 2010. Data collection was through paper and pencil forms. A total of 164 surveys were collected from February 18, 2011 to June 25, 2011. The majority of the interviews were conducted in faith-based institutions ( $\mathrm{n}=115,70 \%)$, while the other $30 \%$ were in community centers and educational facilities. The survey took approximately 25 minutes to administer including the seven minutes allotted for the S-TOFHLA. At the end of the survey, participants were provided a $\$ 15$ incentive. No information in the survey can be linked to any respondent identifying information.

\subsection{Participants}

There were a total of 164 survey participants. Generally survey participants were female (72\%) and overwhelmingly African-American (97\%). Almost half the participants were under the age of 45 (48\%). There was a relatively even distribution across education with just at a third of the sample attaining a high school diploma or GED, another third having had between one to three years of college, and the remaining third having at least completed college. The educational background of participants may have contributed to higher than expected health literacy among the sample. Most participants rated their health as either very good (31\%) or good (40\%).

\subsection{Research plan}

The analysis proceeded in three phases. The first was to calculate the S-TOFHLA score for survey participants. Phase two included creating a series of remotely administrable measures (both indices and factor scores) related to health literacy using questions about the respondent's health related experiences from the survey. In phase three, the measures developed in phase two were correlated with the S-TOFHLA score.

\subsubsection{Phase 1: calculating the S-TOFHLA score}

The S-TOFHLA score is calculated by adding together the correct responses made by survey participants to the 36 multiple-choice items. For each multiple-choice item, participants are asked to select the appropriate word to complete the statement. Each correct response receives a score of one and each incorrect response a score of zero such that the overall score ranges from 0 to 36. According to Nurss et al. ${ }^{[30]}$ scores from 0 to 16 are considered inadequate functional health literacy. Scores from 17 to 22 are considered marginal health literacy, and those from 23 to 36 are considered adequate health literacy. The raw S-TOFHLA score is used in the correlation analysis because it is an interval/ratio measure.

Despite attempts to maximize the variability of low and marginal health literacy only 6 percent scored in the inadequate health literacy range. Two percent had marginal scores; and 92 percent had adequate scores. The skewed nature of this distribution to the high end attenuates the variability of the S-TOFHLA in this analysis. This attenuation likely weakens the S-TOFHLA's correlation with other measures. Consequently the correlation analysis is conducted with both the full sample and a subset of the sample where those scoring 35 and 36 on the S-TOFHLA are excluded. Despite limiting the sample size dramatically, the correlation coefficients increase and statistical significance is still attained in this subset analysis.

\subsubsection{Phase 2: developing a remotely administrable measure of health literacy}

The objective in this phase was to use remotely administrable questions related to the respondent's health care experiences from the survey to obtain a measure(s) that would then correlate well with the S-TOFHLA (phase three). To the extent that these questions correlate well with the S-TOFHLA they should, according to the method of criterion validity, measure 
health literacy. To this end a number of questions from the survey were combined into additive indices and factor scores; a summary of these measures as well as question wording can be found in Table 1.

Table 1. Summary of questions and remotely administrable items

\begin{tabular}{|c|c|c|c|}
\hline Questions & Additive Index Name & Factor Score Name & Expectation with S-TOFHLA \\
\hline 4.1, 4.2(r), 4.3 & AI1 & FS1 & Positive correlation \\
\hline \multicolumn{4}{|c|}{$\begin{array}{l}4.1 \text { "How often do you have problems learning about your medical condition because of difficulty understanding written information ... always, often, } \\
\text { sometimes, occasionally, or never?" }\end{array}$} \\
\hline \multicolumn{4}{|c|}{4.2 “How confident are you filling out medical forms by yourself . . . extremely, quite a bit, somewhat, a little bit, or not at all?” } \\
\hline \multicolumn{4}{|c|}{$\begin{array}{l}4.3 \text { "How often do you have someone (like a family member, friend, hospital/clinic worker, or caregiver) help you read hospital materials ... always, } \\
\text { often, sometimes, occasionally, or never?” }\end{array}$} \\
\hline 5.1, 5.2, 5.3(r) & AI2 & FS2 & Negative correlation \\
\hline \multicolumn{4}{|c|}{$\begin{array}{l}5.1 \text { "How comfortable are you talking to a doctor about your health ... very comfortable, somewhat comfortable, only a little comfortable, or not very } \\
\text { comfortable at all?" }\end{array}$} \\
\hline \multicolumn{4}{|c|}{$\begin{array}{l}5.2 \text { “How comfortable are you talking to other health care providers about your health ... very comfortable, somewhat comfortable, only a little } \\
\text { comfortable, or not very comfortable at all?” }\end{array}$} \\
\hline \multicolumn{4}{|c|}{$\begin{array}{l}5.3 \text { "When you speak with a doctor or other health care providers, do you find it difficult to understand them . . . almost all of the time, most of the time, } \\
\text { only some of the time, or almost none of the time?" }\end{array}$} \\
\hline $5.7 \mathrm{a}-\mathrm{f}$ & AI3 & & Negative correlation \\
\hline \multicolumn{4}{|c|}{5.7 “Generally speaking, when you might have difficulty understanding a doctor or another other health care provider, do you ever ...” } \\
\hline \multicolumn{4}{|c|}{ a. "Ask the doctor or health provider to write down what he/she is saying?" } \\
\hline \multicolumn{4}{|c|}{ b. "Talk to a nurse or someone else who works in the clinic?" } \\
\hline \multicolumn{4}{|c|}{ c. “Talk to someone else like a friend or a relative?” } \\
\hline \multicolumn{4}{|c|}{ d. "Bring someone else with you to the clinic?” } \\
\hline \multicolumn{4}{|c|}{ e. "Schedule another visit to the clinic?" } \\
\hline & & & \\
\hline
\end{tabular}
$5.9,5.10$
AI4
Negative correlation

5.9 "When you receive brochures, pamphlets or other papers from a doctor, hospital or clinic, do you typically read . . . almost all of it, most of it, only some of it, or almost none of it?"

5.10 "When you read brochures, pamphlets or other papers from a doctor, hospital or clinic, do you feel like the information is easy to understand almost all of the time, most of the time, only some of the time, or almost none of the time . . . almost all of the time, most of the time, only some of the time, or almost none of the time?"
4.1, 4.2(r), 4.3, 5.1(r), 5.2(r), 5.3
FS5
Positive correlation
5.7b, 5.9(r), 5.10(r)
FS6
Positive correlation
4.1, 4.2(r), 5.1(r), 5.3
FS7
Positive correlation

Note. (r) denotes that it was necessary to reverse the values of the variable so that it would be aligned in the same direction as the other variables in the index or factor score.

Questions 4.1, 4.2, and 4.3 were taken from Chew et al. ${ }^{[31]}$ and refer to understanding written information, confidence in filling out medical forms, and having someone assist with reading medical materials. These questions were combined into the AI1 index and the FS1 factor score. AI1 ranged from a minimum score of three to a maximum score of fifteen where three would indicate the most difficulty with health literacy and fifteen the least difficulty with health literacy. The expectation was that AI1 and FS1 would positively correlate with the S-TOFHLA.

Questions 5.1, 5.2, and 5.3 were taken from the Assessment of Functional Health Literacy study ${ }^{[32]}$ and deal with comfort issues and difficulty understanding the doctor. They were combined into the AI2 index and the FS2 factor score. AI2 ranged from a low value of three to a high value of eleven where three represents the least difficulty with health literacy and eleven represents the most difficulty with health literacy. The expectation here was that AI2 and FS2 would negatively correlate with the S-TOFHLA.

Questions 5.7 a thru $\mathrm{f}^{[32]}$ represented coping mechanisms used when having difficulty understanding a doctor or other health care provider. These questions were combined into AI3 creating an index score from zero to five. A score of zero indicated that the participant had not used any of the coping mechanisms; whereas, a score of five indicated that the 
participant had used all five of the coping mechanisms when trying to understand a doctor or other health care provider. AI3 was expected to negatively correlate with the S-TOFHLA.

The final additive index was AI4 composed of questions 5.9 and $5.10^{[32]}$. These questions asked about how much hospital documentation the participant typically read and how well they understood it. AI4 ranged from two to seven where two indicated the least difficulty with health literacy and seven indicated the most difficulty with health literacy. AI4 was expected to negatively correlate with the S-TOFHLA.

In addition to the additive indices and factor scores above, subsets of these same questions were combined into three additional measures represented by factor scores FS4, FS5, and FS6. FS4 combined items 4.1, 4.2, 4.3, 5.1, 5.2, and 5.3. FS5 was composed of questions 5.7b, 5.9, and 5.10. And, FS6 combined questions 4.1, 4.2, 5.1, and 5.3. Finally, while not initially planned, questions 4.1, 4.2, and 4.3 were used individually as possible single remotely administrable measures of health literacy.

\section{Results}

\section{Phase 3: correlating the remotely administrable measures with the S-TOFHLA}

Table 2 presents the results of the correlation analysis. As indicated, each index, factor score, and individual question identified in phase 2 were correlated with two measurements of the S-TOFHLA. The first measurement is the raw S-TOFHLA score that ranges from 0-36 where zero indicates exceptionally poor functional health literacy and 36 indicates very good functional health literacy. The second measurement modifies the S-TOFHLA to exclude those participants that scored either a 35 or a 36 due to the attenuation that reduces the variability in the measurement. As seen in Table 2, the measures, AI1, FS1, and 4.2 that were significantly related to the S-TOFHLA remained significant (albeit at slightly lower confidence levels) when correlated with the modified S-TOFHLA score. The analysis using the modified S-TOFHLA score is better able to show the relationship between the remotely administrable measures despite the reduced number of cases.

Table 2. Correlation of remotely administrable items with S-TOFHLA and modified S-TOFHLA

\begin{tabular}{|c|c|c|c|c|c|c|}
\hline \multirow{2}{*}{$\begin{array}{l}\text { Index or } \\
\text { Factor Score }\end{array}$} & \multicolumn{3}{|c|}{ S-TOFHLA } & \multicolumn{3}{|c|}{$\begin{array}{c}\text { Modified S-TOFHLA } \\
\text { (those scoring } 35 \text { or } 36 \text { excluded) }\end{array}$} \\
\hline & $r$ & sig. & $\mathbf{N}$ & $r$ & sig. & $\mathbf{N}$ \\
\hline AI1 & 0.3029 & $0.0002^{* * *}$ & 164 & 0.4181 & $0.0060^{* *}$ & 51 \\
\hline AI2 & -0.0124 & 0.9980 & 164 & -0.0865 & 0.9064 & 51 \\
\hline AI3 & -0.0376 & 0.9562 & 150 & 0.1536 & 0.9007 & 44 \\
\hline AI4 & -0.1199 & 0.6325 & 143 & -0.0174 & 1.0000 & 45 \\
\hline FS1 & 0.3046 & $0.0011^{* *}$ & 164 & 0.4242 & $0.0284^{*}$ & 51 \\
\hline FS2 & -0.0050 & 1.0000 & 164 & -0.0903 & 1.0000 & 51 \\
\hline FS5 & 0.1834 & 0.0553 & 164 & 0.3184 & 0.0542 & 51 \\
\hline FS6 & 0.0158 & 0.9969 & 138 & 0.1072 & 0.8746 & 42 \\
\hline FS7 & 0.1839 & 0.0542 & 164 & 0.2949 & 0.1031 & 51 \\
\hline 4.1 & 0.1754 & 0.4078 & 164 & 0.2936 & 0.5423 & 51 \\
\hline 4.2(r) & 0.2913 & $0.0032^{* *}$ & 164 & 0.4223 & $0.0416^{*}$ & 51 \\
\hline 4.3 & 0.2319 & 0.0575 & 164 & 0.2845 & 0.6029 & 51 \\
\hline
\end{tabular}

${ }^{*}$ significant at $p<.05 ;{ }^{* *}$ significant at $p<.01 ;{ }^{* * *}$ significant at $p<.001$

All of the remotely administrable measures possessed the predicted direction except for AI3 when correlated with the modified S-TOFHLA. However, only two variables attain statistical significance in the analysis: AI1 which is the additive 
index of the three questions from Chew et al. ${ }^{[31]}$, FS1 created from the same three questions, and question 4.2 by itself. Both AI1 and FS1 are essentially equivalent in regards to the S-TOFHLA and the modified S-TOFHLA. When correlated with the S-TOFHLA, AI1 has a significant $r$ of 0.3029 while FS1 has a significant $r$ of 0.3046 . When correlated with the modified S-TOFHLA the r's increase similarly for both variables with AI1 attaining a significant correlation of 0.4181 and FS1 attaining a significant correlation of 0.4242. The correlation coefficient's in both cases are less than initially anticipated by the research. But particularly in the case of the modified S-TOFHLA represent a moderately strong relationship.

Given the correlation of AI1 with both S-TOFHLA measures, additional analysis was conducted for each individual question from AI1 (4.1, 4.2, and 4.3) to see how well they would correlate independently. These results can be seen at the bottom of Table 2 and suggest that it is not necessary to combine these measures into an additive index or factor score. Indeed, question 4.2 is the real standout, it significantly correlates with the S-TOFHLA, $r$ 0.2914, and the modified S-TOFHLA $r$ 0.4223. These correlation coefficients are essentially equivalent to the correlations attained by AI1 and FS1 for both S-TOFHLA measures.

\section{Discussion}

The primary expectation was that a combination of the questions administered in the survey could be identified and combined into a remotely administrable measure that could then be validated as a measure of health literacy by correlating with the S-TOFHLA. Although the indices and factor analysis revealed a number of potential combinations of the questions, only AI1 and FS1 composed of the three questions 4.1, 4.2, and 4.3 identified by Chew et al. ${ }^{[31]}$ showed any promise in terms of being significantly correlated with the S-TOFHLA. Further, when AI1 and FS1 were broken down and the individual questions tested, the analysis revealed that question 4.2 was key to the correlation with the S-TOFHLA.

Although intending to identify a series of questions, it is quite promising to identify that a single question is at least moderately correlated with the S-TOFHLA. The original intent of Chew et al. ${ }^{[31]}$ was to develop a short series of questions that could be applied in a medical setting to quickly determine the health literacy of patients. The intent of this research was to develop a series of questions that could be remotely administered to assess health literacy in broad populations. Essentially question 4.2, "How confident are you in filling out medical forms by yourself?" may hold the key to each of these enterprises. In moving forward, there are a number of avenues for further research since the correlation between question 4.2 and the S-TOFHLA, as strong as it is, is likely not sufficient for the measure to be used in isolation.

First, these results may be due to the strong skew in the S-TOFHLA toward the high end of functional health literacy found in this non-representative convenience sample. Other samples using the S-TOFHLA with better variation among a larger $\mathrm{N}$ may reveal stronger correlation with question 4.2 and thereby justify its use as a single measure.

Second, the lack of success may be due to inherent deficiencies in the S-TOFHLA as a measure of health literacy if its procedures consistently produce skewed distributions. Thus, additional research correlating question 4.2 with different measures of health literacy (e.g., REALM) may reveal stronger correlation.

Third, despite the success of question 4.2, concepts such as health literacy are inherently complex and multi-dimensional. Consequently, it is reasonable to assume that the development of additional questions that could be combined with question 4.2 might enhance its correlation with health literacy measures and thus produce a better overall remotely administrable measure of health literacy. While the additional questions used in this research were unable to produce such an effect, this research advances that goal by demonstrating which questions were ineffective in developing such a measure. While using a single question such as 4.2 as a remotely administrable measure of health literacy would be ideal, it is most likely that a remote measure will be composed of a series of at least three to six questions. Such a measure would satisfy Chew et al.'s ${ }^{[31]}$ search for a series of questions that could be used in-person at the time of clinical treatment and 
this research's search for a series of questions that could be used in either mail or telephone surveys to assess health literacy in broader populations.

\section{Conclusion}

The following then are the key findings from this research. First, a single measure, question 4.2, does an adequate job of assessing health literacy based on its non-random and moderate correlation with the S-TOFHLA. This question can be easily administered in a number of formats such as in-person or remotely by either telephone or mail survey. There is however room to improve this measure. Additional testing both with the S-TOFHLA in different populations and with different measures of health literacy may help to validate the use of this question as a single item indicator of health literacy. Finally, it is likely that there may be other questions that can be combined with question 4.2 to enhance its validity as a measure of health literacy.

\section{Acknowledgments}

The project described was supported by Award Number P20MD002314 from the National Center on Minority Health and Health Disparities. The content is solely the responsibility of the authors and does not necessarily represent the official views of the National Center on Minority Health and Health Disparities or the National Institutes of Health.

\section{References}

[1] Kirsch I, Jungeblut A, Jenkins L, Kolstad A. Adult Literacy in America. Washington D.C.: U.S. Department of Education, Office of Educational Research and Improvement. 1993.

[2] Rudd RE, Moeykens BA, Colton TC. Health and Literacy: A Review of Medical and Public Health Literature. In J. Commings, B. Garners, and C. Smith (eds.). Annual Review of Adult Learning and Literacy. New York, NY: Jossey-Bass. 1999.

[3] National Center for Education Statistics (NCES). National Assessment of Adult Literacy. 2003. Retrieved online 4/28/09 from http://nces.ed.gov/naal/health_results.asp

[4] Institute of Medicine (IOM). Health Literacy: A Prescription to End Confusion. Washington D.C.: National Academies Press. 2004.

[5] Schwartzbert JG, VanGeest JB, Wang CC. (eds.). Understanding Health Literacy: Implications for Medicine and Public Health. American Medical Association Press. 2005.

[6] Weiss BD. Epidemiology of Low Literacy. In Schwartzberg J, VenGeest J, Wang C, (eds.). Understanding Health Literacy: Implications for Medicine and Public Health. American Medical Association Press. 2005; 17-42.

[7] Weiss BD, Coyne C. Communicating with Patients Who Cannot Read. The New England Journal of Medicine. 1997; 337(4): 272-4. PMid: 9227936. http://dx.doi.org/10.1056/NEJM199707243370411

[8] Rudd R, Kirsch L, Yamamoto K. Literacy in Health Contexts: A Re-Analysis of the NALS. 2003. American Public Health Association Annual Conference Session 4182.1. Washington D.C., American Public Health Association.

[9] Paasche-Orlow MK, Taylor HA, Brancati FL. Readability Standards for Informed-Consent Forms as Compared with Actual Readability. The New England Journal of Medicine. 2003; 348: 721-6. PMid: 12594317.

http://dx.doi.org/10.1056/NEJMsa021212

[10] Ad Hoc Committee on Health Literacy for the Council on Scientific Affairs. Health Literacy: A Report of the Council on Scientific Affairs. Journal of the American Medical Association. 1999; 281(6): 552-7. PMid: 10022112. http://dx.doi.org/10.1001/jama.281.6.552

[11] Weiss BD, Hart G, McGee DL, D’Estelle S. Health Status of Illiterate Adults: Relation Between Literacy and Health Status Among Persons with Low Literacy Skills. Journal of the American Board of Family Practice. 1992; 5(3): 257-64. PMid: 1580173.

[12] Baker DW, Parker RM, Williams MV, Clark WS, Nurss J. The Relationship of Patient Reading Ability to Self-Reported Health and Use of Health Services. American Journal of Public Health. 1997; 87(6): 1027-30. PMid: 9224190.

http://dx.doi.org/10.2105/AJPH.87.6.1027

[13] Kalichman SC, Rompa D. Functional Health Literacy is Associated with Health Status and Health Related Knowledge in People Living with HIV-AIDS. Journal of Acquired Immune Deficiency Syndrome. 2000; 25: 337-44. http://dx.doi.org/10.1097/00126334-200012010-00007 
[14] Bennett CL, Ferreira MR, Davis TC, et al. Relation between Literacy, Race, and Stage of Presentation Among Low-Income Patients with Prostate Cancer. Journal of Clinical Oncology. 1998; 16: 3101-4. PMid: 9738581.

[15] Williams MV, Baker DW, Honig EG, Lee TM, Nowlan A. Inadequate Literacy is a Barrier to Asthma Knowledge and Self-Care. Chest. 1998a; 114(4): 1008-15. PMid: 9792569. http://dx.doi.org/10.1378/chest.114.4.1008

[16] Williams MV, Baker DW, Parker RM, Nurss J. Relationship of Functional Health Literacy to Patients' Knowledge of Their Chronic Disease: A Study of Patients with Hypertension or Diabetes. Archives of Internal Medicine. 1998b; 158(2): $166-172$. PMid: 9448555. http://dx.doi.org/10.1001/archinte.158.2.166

[17] Baker DW, Parker RM, Williams MV, Clark WS, Nurss J. The Relationship of Patient Reading Ability to Self-Reported Health and Use of Health Services. American Journal of Public Health. 1997; 87(6): 1027-30. PMid: 9224190. http://dx.doi.org/10.2105/AJPH.87.6.1027

[18] Baker DW, Parker RM, Williams MV, Clark WS. Health Literacy and the Risk of Hospital Admission. Journal of General Internal Medicine. 1998; 13: 791-8. PMid: 9844076. http://dx.doi.org/10.1046/j.1525-1497.1998.00242.x

[19] Baker DW, Gazmararian JA, Williams MV, et al. Functional Health Literacy and the Risk of Hospital Admission Among Medicare Managed Care Enrollees. American Journal of Public Health. 2002; 92: 1278-1283. PMid: 12144984. http://dx.doi.org/10.2105/AJPH.92.8.1278

[20] Davis TC, Byrd RS, Arnold CL, Auinger P, Bocchini JA. Low Literacy and Violence Among Adolescents in a Summer Sports Program. Journal of Adolescent Health. 1999; 24(6): 403-11. http://dx.doi.org/10.1016/S1054-139X(98)00148-7

[21] Tuckson RV. National Conference on Health Literacy: Keynote Address. Health Literacy Proceedings Advancing Public Policy. Washington D.C. 2002.

[22] Weiss BD, Blanchard JS, McGee DL, Hart G, Warren B, Burgoon M, et al. Illiteracy Among Medicaid Recipients and Its Relationship to Health Care Costs. Journal of Health Care for the Poor and Underserved. 1994; 5(2): 99-111. PMid: 8043732. http://dx.doi.org/10.1353/hpu.2010.0272

[23] Weiss BD, Palmer R. Relationship between Health Care Costs and Very Low Literacy Skills in a Medically Needy and Indigent Medicaid Population. Journal of the American Board of Family Practice. 2004; 17: 44-7. http://dx.doi.org/10.3122/jabfm.17.1.44

[24] Howard DH, Gazmararian J, Parker RM. The Impact of Low Health Literacy on the Medical Costs of Medicare Managed Care Enrollees. American Journal of Medicine. 2005; 118: 371-7. PMid: 15808134. http://dx.doi.org/10.1016/j.amjmed.2005.01.010

[25] Davis TC, Kennen EM, Gazmararian JA, Williams MV. Literacy Testing in Health Care Research. In Schwartzberg J, VenGeest J, Wang C, (eds.). Understanding Health Literacy: Implications for Medicine and Public Health. American Medical Association Press. 2005; 157-179.

[26] Fowler FJ. Survey Research Methods, 3rd ed. Thousand Oaks, CA: Sage Publications. 2002; 58-75. PMid: 11843075.

[27] Carmines EG, Zeller RA. Reliability and Validity Assessment. Thousand Oaks, CA: Sage Publications. 1979. http://dx.doi.org/10.4135/9781412985642

[28] Streiner DL, Norman GR. Health Measurement Scales, 3rd ed. Oxford University Press. 2003; 172-8.

[29] Powers BJ, Trinh JV, Hayden B. Can This Patient Read and Understand Written Health Information? JAMA. 2010; $304(1): 76-84$. PMid: 20606152. http://dx.doi.org/10.1001/jama.2010.896

[30] Nurss JR, Parker RM, Williams MV, Baker DW. 2011. TOFHLA: Test of Functional Health Literacy in Adults. Hartford, MI: Peppercorn Books and Press, Inc.

[31] Chew LD, Bradley K, Boyko E. Brief Questions to Identify Patients with Inadequate Health Literacy. Family Medicine. 2004; 36(8): 588-94. PMid: 15343421.

[32] Wells VE, Chenier T, Ludke RL, Downing K, Shaw T. An Assessment of Functional Health Literacy Among Patients Served in Primary Care Providers to Poor Practice Settings. Cincinnati, OH: Institute for Health Policy and Health Services Research, University of Cincinnati Medical Center. 2001. 